\title{
The Effect of Probiotics on Bacterial Pneumonia
}

\author{
Ahmad Najafi $^{1,{ }^{*}}$, Alireza Sharif ${ }^{1}$, Mohammadreza Sharif ${ }^{2}$ and Hamidreza Gilassi ${ }^{3}$ \\ ${ }^{1}$ Department of Infectious Diseases, Faculty of Medicine, Kashan University of Medical Sciences, Kashan, Iran \\ ${ }^{2}$ Department of Pediatrics, Faculty of Medicine, Kashan University of Medical Sciences, Kashan, Iran \\ ${ }^{3}$ Faculty of Medicine, Kashan University of Medical Sciences, Kashan, Iran \\ "Corresponding author: Department of Infectious diseases, Faculty of Medicine, Kashan University of Medical Sciences, Kashan, Iran. Email: a.najafi1975@yahoo.com
}

Received 2019 September 08; Revised 2020 January 02; Accepted 2020 January 05.

\begin{abstract}
Background: Pneumonia, as a fairly prevalent illness, is the main cause of hospital mortality. The major cause of mortality and morbidity of pneumonia is due to bacteria. The presence of multi-drug resistant pathogens and no response to treatment have aroused considerable interest in the use of probiotic components to prevent infections.

Objectives: Given that few studies have evaluated the efficacy of probiotics in reducing bacterial pneumonia, the current aimed to evaluate the role of probiotics in decreasing pneumonia.

Methods: This double-blind, randomized clinical trial study was conducted on 100 patients diagnosed with bacterial pneumonia in Shahid Beheshti Hospital, Kashan, Iran, during 2018. Patients were randomly classified into two groups ( $\mathrm{n}=50$ ). One group (case) received two sachets of probiotic/daily for five days, and another group (control) received placebo. Moreover, patients in both groups received the same treatment protocol. All data were extracted from medical records. Chi-square test and independent $t$-test were used for analysis of data. $\mathrm{P}<0.05$ was considered statistically significant.

Results: No significant difference was seen between case and control groups regarding age, gender, and duration of symptoms before hospitalization ( $\mathrm{P}>0.05$ ), which implies a completely random classification of two groups. The mean duration of hospitalization, dyspnea, tachypnea, cough, fever, and crackles was significantly decreased in the case group compared to the control group $(\mathrm{P}<0.05)$.

Conclusion: The use of probiotics can be effective in reducing the duration of dyspnea, tachypnea, cough, fever, and length of hospitalization. Therefore, probiotics may be considered a promising treatment for the development of new anti-infectious therapy. In addition, the usage of probiotics along with antibiotics is suggested for decreasing pneumonia complications and improving the efficacy of therapy.
\end{abstract}

Keywords: Bacteria, Probiotics, Pneumonia

\section{Background}

Pneumonia is a fairly prevalent illness and a common complication in critically ill patients, especially in patients who are intubated for more than 48 hours $(1,2)$. It is the main cause of hospital mortality (3). The most common findings on physical examination of the disease include tachypnea, tachycardia, fever with or without chills, and decreased bronchial breath sounds (4). Several factors, including age, hospital setting, and comorbidities are considered major factors affecting prognosis (4). Patients younger than four years and older than 60 years have a poorer prognosis than other age groups. Many causes of pneumonia are bacteria, viruses, fungi, and parasites, but bacteria are the major cause of mortality and morbidity by pneumonia (4).

Types of bacterial pneumonia include Community-
Acquired Pneumonia or CAP(acute infection of lung tissue, which has been acquired from the community), HospitalAcquired Pneumonia or HAP (acute infection of lung tissue that develops 48 hours or more after hospitalization), healthcare-associated pneumonia or HCAP (acute infection of lung tissue acquired from health center or in patients hospitalized within the past 3 months), and VAP or ventilator-associated pneumonia (nosocomial infection of lung tissue that develops 48 hours or longer after intubation of mechanical ventilation). The most common complications of bacterial pneumonia are sepsis, multiorgan failure, respiratory failure, and coagulopathy (4).

Studies have shown that selective digestive tract decontamination decreases the occurrence of pneumonia; however, such decontamination is associated with increased rates of antimicrobial resistance $(5,6)$. Recently, some studies have proposed a promising effect of probiotics on 
preventing pneumonia in patients (7-10).

Probiotics are commercial microorganisms that may have health benefits to individuals when ingested (1113). Prebiotics colonize the host's gastrointestinal tract, change microbiota (10, 14-22), and exert antibacterial effects. They create an undesirable environment for pathogens via the following mechanisms, including the promotion of gut's defense barrier (via normalization of permeability of intestine), modulation of secretory immunoglobulin action, and intestinal inflammatory responses, preservation of normal gastrointestinal flora, maintenance of antibacterial effects (by alteration of local pH, nutrient competition, modification of pathogenderived toxins, and stimulation of epithelial mucin production) (10). Probiotic components are used in several forms, such as fortified dairy drinks and food supplements for health benefits. Several studies have shown the role of probiotics administration in numerous infectious illnesses such as wound infections, abscesses, endocarditis, bacteremia, and pneumonia (23-30).

Probiotic components are used in many cultures for health benefits (10). These bacterial components can be a precious additive against increasingly antibiotic-resistant pathogens. Moreover, they are easy, cheap, and available (10).

Recent studies demonstrated that administrating probiotics to patients with mechanical ventilation leads to reducing the incidence of ventilator-associated pneumonia and the incidence of all nosocomial infections $(31,32)$. Given that most studies have assessed the role of probiotics for the prevention of respiratory infections and ventilatorassociated pneumonia (VAP) in intensive care unit $(32,33)$ and few studies have found the efficacy of probiotics in reducing bacterial pneumonia, and no comprehensive study has been conducted in this regard in our region, the aim of the current study was to evaluate the role of probiotics in bacterial pneumonia.

\section{Methods}

\subsection{Selecting of Patients}

This double-blind, randomized clinical trial study was conducted on patients diagnosed with bacterial pneumonia in Shahid Beheshti Hospital, Kashan, Iran, in 2018. After obtaining informed consent from the patients, the current study was approved by the Ethics Committee of Kashan University of Medical Sciences, and 100 patients with bacterial pneumonia were enrolled.

\subsection{Inclusion and Exclusion Criteria}

Age over 12 years and clinical diagnosis of bacterial pneumonia based on clinical criteria, including fever, pleu- ral chest pain, cough, tachypnea, presence of parenchymal involvement in chest radiography, and shortness of breath, were considered the inclusion criteria. Heart failure and other diseases that cause lung edema or other pulmonary disorders were considered the exclusion criteria. Moreover, intolerance or allergy to probiotics, unwillingness to participate in the study, and no hospitalization in the intensive care unit (ICU) were other exclusion criteria.

\subsection{Classifying of Patients into the Intervention and Control Groups}

Patients were randomly classified into two groups ( $\mathrm{n}=$ 50). The first group received two sachets of probiotic/daily for 5 days. Each probiotic sachet included probiotic strains such as, Lactobacillus rhamnosus, Lactobacillus casei, Lactobacillus acidophilus, Lactobacillus bulgaricus, Bifidobacterium breve, Bifidobacterium infantis, Streptococcus thermophiles, and Prebiotics such as Fructo-oligosaccharide (Biology fermentation company), and the second group received placebo (Farabi company). Moreover, all patients in the pediatric ward received ceftriaxone ( $50 \mathrm{mg} / \mathrm{kg}$ once daily) and patients in the infectious ward received ceftriaxone (1g/12 hours) with azithromycin.

\subsection{Extraction of Data}

Data, including age, gender, duration of symptoms before hospitalization, duration of dyspnea, duration of tachypnea, duration of cough, duration of fever, duration of hospitalization and crackles, were extracted from medical records.

\subsection{Statistical Analysis}

Data were entered SPSS, version 16. Chi-square test and independent $t$-test were used for analysis of data. P-value of less than 0.05 was considered statistically significant.

\section{Results}

Table 1 shows the comparison of two groups (case and control groups) in terms of gender.

As demonstrated in Table 1, no significant difference was observed between the two groups, regarding gender $(\mathrm{P}>0.05)$. Moreover, the mean age of the patients in the case and control groups was $41.46 \pm 18.12$ and $44.82 \pm$ 21.39, respectively $(P=0.39)$. However, no significant difference was seen between the case $(5.62 \pm 2.09)$ and control groups ( $5.78 \pm 2.08$ ), regarding the duration of symptoms before hospitalization $(\mathrm{P}=0.70)$. These findings showed that there was no significant difference between the two groups in terms of sampling. This implies a completely random classification into two groups. Table 2 shows the 


\begin{tabular}{lccc}
\hline Table 1. Comparison of Two Groups in Terms of Gender ${ }^{\text {a }}$ & \\
\hline & Probiotic (Case) & Control (Control) & P-Value $^{\text {b }}$ \\
\hline Gender & & & 0.423 \\
& & & \\
Male & $24(48)$ & $28(56)$ & \\
Female & $26(52)$ & $22(44)$ & \\
Total & $50(100)$ & $50(100)$ & \\
\hline
\end{tabular}

${ }^{\mathrm{a}}$ Values are expressed No. (\%).

${ }^{\mathrm{b}}$ Chi-square test.

comparison of the two groups regarding the characteristics of the patients.

As shown in Table 2, a significant difference was seen between the two groups regarding duration of hospitalization, dyspnea, tachypnea, cough, fever, and crackles ( $P$ $<0.05)$.

\section{Discussion}

Probiotic components are used in many cultures for health benefits. These products can be a valuable additive against antibiotic-resistant pathogens. They have numerous antibacterial and immunomodulatory actions (10). Most studies have assessed the function of probiotics in ventilator-induced pneumonia prevention. Zarrinfar et al. assessed the role of probiotics in the prevention of ventilator-induced pneumonia. The finding of this study showed that the use of probiotics decreases ventilatorassociated pneumonia, as well as the mean days of admission in ICU and hospital (34). They believed that this therapy should be used in the patient's candidate for long-term intubation. Zeng et al. evaluated the effect of probiotics in the incidence of ventilator-associated pneumonia in critically ill patients. Their findings showed that treatment with probiotics is an effective and safe method for the prevention of VAP (35). Banupriya et al. achieved the same results and reported that probiotics administration reduced the incidence of VAP in critically ill children (36).

Our study showed that the duration of dyspnea, tachypnea, cough, crackles, and duration of hospitalization were decreased in case groups compared to the control group. Given that the mean length of stay for pneumonia in our study was five days and these patients were discharged from hospital 24 to 48 hours after ceasing fever, cough, and shortness of breath, and access to these patients was difficult after discharge, the mean probiotic intake was considered five days. Li et al. assessed characteristics of patients receiving probiotics and observed that probiotics improve the efficacy of amoxicillin against breathing pneumonia (37). Moreover, they observed that cough, fever, and tachypnea were decreased in patients receiving probiotics in comparison to the placebo group. The findings of this study were consistent with the findings of the present study. Siempos et al. reported that administration of probiotics was effective in the prevention of nosocomial pneumonia, duration of hospitalization in ICU, and colonization rate of Pseudomonas aeruginosa in the respiratory tract (38). Pitsouni et al. showed that probiotics decreased the occurrence of pneumonia and infectious complications as well as the duration of hospitalization (39).

The findings of this study were also consistent with the findings of our study. Wang et al. reported that the probiotic component decreases the incidence of respiratory tract infections in children (40). Shida et al. reported that daily intake of Lactobacillus casei strain Shirota with fermented milk may decrease the risk of upper respiratory tract infections by modulation of the immune system in healthy middle-aged (41).

Heidarian et al. showed that the beneficial effect of probiotics on preventing nosocomial infections is more prominent in patients who are hospitalized over 72 hours in hospital (42). Ling et al. evaluated the effect of probiotics in the prevention of pneumonia in children and did not observe antibiotic-associated diarrhea and other adverse events in these children. Moreover, they observed that the use of probiotics is effective in preventing complications in children treated with azithromycin (43). Wolvers et al. reported that probiotics may decrease different symptoms of respiratory tract infections, including ear, nose, and throat infections in children and adults (7). Accordingly, the use of probiotics is considered a promising therapy for infection.

Watkinson et al. demonstrated that the use of pre-, pro, or synbiotics was not related to the incidence of nosocomial pneumonia in all subgroups; however, the risk of reduction with probiotics was considerable (44).

Other study reported., reported that probiotics, compared to placebo, have better efficacy in the treatment of upper respiratory tract acute infection episodes, which leads to a decrease in the use of antibiotics (45). Moreover, they reported that probiotics could operate against pathogenic bacteria via creating antimicrobial agents such as organic acids, hydrogen peroxide, and bacteriocin $(14,46,47)$, competing for cellular adhesion sites and preventing the production of viral factors. In addition, these components can be effective against pathogens through interacting with the host, reinforcing the action of the epithelium barrier, and changing the immune system answer $(14,46,47)$.

Li et al. found that probiotics in combination with amoxicillin-sulbactam are more effective in the treatment of childhood breathing pneumonia (37). Guo et al. re- 


\begin{tabular}{|c|c|c|c|}
\hline Parameters & Probiotic(Case) & Placebo (Control) & P-Value $^{\text {a }}$ \\
\hline Duration of dyspnea (day) & $2.02 \pm 1.54$ & $3.50 \pm 2.13$ & $<0.001$ \\
\hline Duration of tachypnea (day) & $1.76 \pm 1.22$ & $3.14 \pm 1.85$ & $<0.001$ \\
\hline Duration of cough (day) & $3.78 \pm 1.64$ & $4.98 \pm 2.23$ & 0.002 \\
\hline Duration of fever(day) & $1.86 \pm 1.17$ & $2.48 \pm 1.72$ & 0.042 \\
\hline Duration of crackles (day) & $3.04 \pm 1.42$ & $4.66 \pm 1.95$ & $<0.001$ \\
\hline Duration of hospitalization (day) & $4.16 \pm 1.77$ & $5.34 \pm 2.37$ & 0.005 \\
\hline
\end{tabular}

ported that oral administration of probiotics reduces pneumonia, while increases pulmonary functions without severe adverse effects. Moreover, no significant difference was seen between patients receiving probiotics than patients receiving placebo in terms of incidence of adverse events (48). On the other hand, Box et al. assessed the effect of lactobacillus probiotics on the rate of Clostridium difficile infection in patients receiving antibiotics and did not observe a difference between those who received probiotics and those who did not receive probiotic in terms of the infection (49). It seems that the dosage of medication, duration of the treatment, type of probiotics, and type of the disease are the reasons for the difference between various studies.

In our study, although we did not evaluate the mechanism of probiotics, Ashraf et al. reported that the use of probiotic supplementation can prevent immunemediated diseases during childhood. Nevertheless, this intervention during pregnancy can affect fetal immune parameters, including transforming growth factor-beta (TGF$\beta 1$ ) level, cord blood interferon-gamma (IFN- $\gamma$ ) level, and breast milk immunoglobulin A (IgA). It seems that the immune system is stimulated by probiotic microorganisms (50).

Determination of the type of bacterium was not possible in our study; therefore, it may be considered a limitation of the study, but intervention in the two groups was done in the same conditions. In addition, suspected cases of tuberculosis and MDR were excluded from the study. Cases with severe pneumonia that required hospitalization in NICU were not also entered the study to decrease bias in the current study.

\subsection{Conclusion}

The use of probiotics can be effective in reducing the duration of dyspnea, tachypnea, cough, fever, and length of hospitalization. Therefore, probiotics may be considered a promising treatment for the development of new anti-infectious therapy. In addition, the usage of probiotics, along with antibiotics, is suggested for decreasing pneumonia-associated complications and improving the efficacy of therapy. However, further studies are needed to evaluate the therapeutic effects of probiotics.

\section{Acknowledgments}

We thank the staff of Shahid Beheshti Hospital for their kind contribution to the current study.

\section{Footnotes}

Authors' Contribution: Given that most studies have assessed the role of probiotics for prevention of respiratory infections and ventilator-associated pneumonia (VAP) in intensive care unit and few studies have found the efficacy of probiotics in reducing bacterial pneumonia and no comprehensive study has been conducted in this regard in our region, the aim of current study was to evaluate the role of probiotics in bacterial pneumonia

Clinical Trial Registration Code: IRCT 20200107046047 N1.

Conflict of Interests: None

Ethical Approval: IR. KAUMS.MEDNT.REC.1396. 101

Funding/Support: None

Informed Consent: Informed consent was obtained from the patients before the study.

\section{References}

1. Jain V, Bhardwaj A. Pneumonia pathology. Treasure Island (FL): StatPearls Publishing; 2019. p. 1-10.

2. Mackenzie G. The definition and classification of pneumonia. Pneumonia (Nathan). 2016;8:14. doi: 10.1186/s41479-016-0012-z. [PubMed: 28702293]. [PubMed Central: PMC5471962]. 
3. Liu KX, Zhu YG, Zhang J, Tao LL, Lee JW, Wang XD, et al. Probiotics' effects on the incidence of nosocomial pneumonia in critically ill patients: a systematic review and meta-analysis. Crit Care. 2012;16(3):R109. doi: 10.1186/cc11398. [PubMed: 22731894]. [PubMed Central: PMC3580667].

4. Bin S, Sattar A, Sharma S. Bacterial pneumonia. Treasure Island (FL): StatPearls Publishing; 2019.

5. Oostdijk EA, de Smet AM, Blok HE, Thieme Groen ES, van Asselt GJ, Benus RF, et al. Ecological effects of selective decontamination on resistant gram-negative bacterial colonization. Am J Respir Crit Care Med. 2010;181(5):452-7. doi: 10.1164/rccm.200908-12100C. [PubMed: 19965807].

6. Oudhuis GJ, Bergmans DC, Dormans T, Zwaveling JH, Kessels A, Prins $\mathrm{MH}$, et al. Probiotics versus antibiotic decontamination of the digestive tract: infection and mortality. Intensive Care Med. 2011;37(1):1107. doi: 10.1007/s00134-010-2002-6. [PubMed: 20721536]. [PubMed Central: PMC3020315].

7. Wolvers D, Antoine JM, Myllyluoma E, Schrezenmeir J, Szajewska H, Rijkers GT. Guidance for substantiating the evidence for beneficial effects of probiotics: prevention and management of infections by probiotics. J Nutr. 2010;140(3):698S-712S. doi: 10.3945/jn.109.113753. [PubMed: 20107143].

8. Schultz MJ, Haas LE. Antibiotics or probiotics as preventive measures against ventilator-associated pneumonia: a literature review. Crit Care. 2011;15(1):R18. doi: 10.1186/cc9963. [PubMed: 21232110]. [PubMed Central: PMC3222052].

9. Isakow W, Morrow LE, Kollef MH. Probiotics for preventing and treating nosocomial infections: review of current evidence and recommendations. Chest. 2007;132(1):286-94. doi: 10.1378/chest.06-2156. [PubMed: 17625089].

10. McNabb B, Isakow W. Probiotics for the prevention of nosocomial pneumonia: current evidence and opinions. Curr Opin Pulm Med. 2008,14(3):168-75. doi: 10.1097/MCP.ob013e3282f76443. [PubMed: 18427239].

11. Joint FAO/WHO Working Group. Guidelines for the Evaluation of Probiotics in Food. London Ontario, Canada: Joint FAO/WHO Working Group; 2002.

12. Cook DJ, Johnstone J, Marshall JC, Lauzier F, Thabane L, Mehta S, et al. Probiotics: Prevention of severe pneumonia and endotracheal colonization trial-PROSPECT: a pilot trial. Trials. 2016;17:377. doi: 10.1186/s13063-016-1495-x. [PubMed: 27480757]. [PubMed Central: PMC4970233].

13. Joint FAO/WHO Working Group. Guidelines for the Evaluation of Probiotics in Food. Joint FAO/WHO Working Group; 2014.

14. Walker WA. Mechanisms of action of probiotics. Clin Infect Dis. 2008;46 Suppl 2:S87-91. discussion S144-51. doi: 10.1086/523335. [PubMed: 18181730].

15. Forsythe P. Probiotics and lung diseases. Chest. 2011;139(4):901-8. doi: 10.1378/chest.10-1861. [PubMed: 21467057].

16. Isolauri E, Sutas Y, Kankaanpaa P, Arvilommi H, Salminen S. Probiotics: effects on immunity. Am J Clin Nutr. 2001;73(2 Suppl):444S-50S. doi: 10.1093/ajcn/73.2.444s. [PubMed: 11157355].

17. Alberda C, Gramlich L, Meddings J, Field C, McCargar L, Kutsogiannis D, et al. Effects of probiotic therapy in critically ill patients: a randomized, double-blind, placebo-controlled trial. Am J Clin Nutr. 2007;85(3):816-23. doi: 10.1093/ajcn/85.3.816. [PubMed: 17344505].

18. van Minnen LP, Timmerman HM, Lutgendorff F, Verheem A, Harmsen W, Konstantinov SR, et al. Modification of intestinal flora with multispecies probiotics reduces bacterial translocation and improves clinical course in a rat model of acute pancreatitis. Surgery.2007;141(4):470-80. doi:10.1016/j.surg.2006.10.007.[PubMed: 17383524].

19. Madsen K, Cornish A, Soper P, McKaigney C, Jijon H, Yachimec C, et al. Probiotic bacteria enhance murine and human intestinal epithelial barrier function. Gastroenterology. 2001;121(3):580-91. doi: 10.1053/gast.2001.27224. [PubMed: 11522742].
20. Ewaschuk J, Endersby R, Thiel D, Diaz H, Backer J, Ma M, et al. Probiotic bacteria prevent hepatic damage and maintain colonic barrier function in a mouse model of sepsis. Hepatology. 2007;46(3):841-50. doi: 10.1002/hep.21750. [PubMed: 17659579].

21. Zhou HJ, Yin L, Chen CQ, Shi MM, Zhang MJ. Administration of probiotics reduces bacterial translocation after intestinal transplantation in rats. Transplant Proc. 2010;42(10):4643-7. doi: 10.1016/j.transproceed.2010.09.171. [PubMed: 21168752].

22. Schrezenmeir J, de Vrese M. Probiotics, prebiotics, and synbioticsapproaching a definition. Am J Clin Nutr. 2001;73(2 Suppl):361S-4S. doi: 10.1093/ajcn/73.2.361s. [PubMed: 11157342].

23. Husni RN, Gordon SM, Washington JA, Longworth DL. Lactobacillus bacteremia and endocarditis: review of 45 cases. Clin Infect Dis. 1997;25(5):1048-55. doi: 10.1086/516109. [PubMed: 9402355].

24. Rautio M, Jousimies-Somer H, Kauma H, Pietarinen I, Saxelin M, Tynkkynen S, et al. Liver abscess due to a Lactobacillus rhamnosus strain indistinguishable from L. rhamnosus strain GG. Clin Infect Dis. 1999;28(5):1159-60. doi: 10.1086/514766. [PubMed: 10452653].

25. Land MH, Rouster-Stevens K, Woods CR, Cannon ML, Cnota J, Shetty AK. Lactobacillus sepsis associated with probiotic therapy. Pediatrics. 2005;115(1):178-81. doi: 10.1542/peds.2004-2137. [PubMed: 15629999].

26. Kunz AN, Noel JM, Fairchok MP. Two cases of Lactobacillus bacteremia during probiotic treatment of short gut syndrome. J Pediatr Gastroenterol Nutr. 2004;38(4):457-8. doi: 10.1097/00005176-20040400000017. [PubMed: 15085028].

27. Salminen MK, Rautelin H, Tynkkynen S, Poussa T, Saxelin M, Valtonen $\mathrm{V}$, et al. Lactobacillus bacteremia, clinical significance, and patient outcome, with special focus on probiotic L. rhamnosus GG. Clin Infect Dis. 2004;38(1):62-9. doi: 10.1086/380455. [PubMed:14679449].

28. Jones SD, Fullerton DA, Zamora MR, Badesch DB, Campbell DN, Grover FL. Transmission of Lactobacillus pneumonia by a transplanted lung. Ann Thorac Surg. 1994;58(3):887-9. doi: 10.1016/0003-4975(94)90779-x. [PubMed: 7944727].

29. Patel R, Cockerill FR, Porayko MK, Osmon DR, Ilstrup DM, Keating MR. Lactobacillemia in liver transplant patients. Clin Infect Dis. 1994;18(2):207-12. doi: 10.1093/clinids/18.2.207. [PubMed: 8161628].

30. Wood GC, Boucher BA, Croce MA, Fabian TC. Lactobacillus species as a cause of ventilator-associated pneumonia in a critically ill trauma patient. Pharmacotherapy. 2002;22(9):1180-2. doi: 10.1592/phco.22.13.1180.33530. [PubMed: 12222555].

31. Petrof EO, Dhaliwal R, Manzanares W, Johnstone J, Cook D, Heyland DK. Probiotics in the critically ill: a systematic review of the randomized trial evidence. Crit Care Med. 2012;40(12):3290-302. doi: 10.1097/CCM.ob013e318260cc33. [PubMed: 22975886].

32. Marshall JC. Gastrointestinal flora and its alterations in critical illness. Curr Opin Clin Nutr Metab Care. 1999;2(5):405-11. doi: 10.1097/00075197-199909000-00009. [PubMed:10589383].

33. Brenchley JM, Douek DC. Microbial translocation across the GI tract. Annu Rev Immunol. 2012;30:149-73. doi: 10.1146/annurev-immunol020711-075001. [PubMed: 22224779]. [PubMed Central: PMC3513328].

34. zarinfar N, sharafkhah M, Amiri M, Rafeie M. Probiotic effects in prevention from ventilator-associated pneumonia. Koomesh Journal. 2016;17(4):803-13.

35. Zeng J, Wang CT, Zhang FS, Qi F, Wang SF, Ma S, et al. Effect of probiotics on the incidence of ventilator-associated pneumonia in critically ill patients: a randomized controlled multicenter trial. Intensive Care Med. 2016;42(6):1018-28. doi: 10.1007/s00134-016-4303-x. [PubMed: 27043237].

36. Banupriya B, Biswal N, Srinivasaraghavan R, Narayanan P, Mandal J. Probiotic prophylaxis to prevent ventilator associated pneumonia (VAP) in children on mechanical ventilation: an open-label randomized controlled trial. Intensive Care Med. 2015;41(4):677-85. doi: 10.1007/s00134-015-3694-4. [PubMed: 25708419].

37. Li B, Zheng J, Zhang X, Hong S. Probiotic Lactobacillus casei Shirota improves efficacy of amoxicillin-sulbactam against childhood 
fast breathing pneumonia in a randomized placebo-controlled double blind clinical study. J Clin Biochem Nutr. 2018;63(3):2337. doi: 10.3164/jcbn.17-117. [PubMed: 30487675]. [PubMed Central: PMC6252301]

38. Siempos ,I, Ntaidou TK, Falagas ME. Impact of the administration of probiotics on the incidence of ventilator-associated pneumonia: a meta-analysis of randomized controlled trials. Crit Care Med.2010;38(3):954-62. doi:10.1097/CCM.0b013e3181c8fe4b. [PubMed: 20016381].

39. Pitsouni E, Alexiou V, Saridakis V, Peppas G, Falagas ME. Does the use of probiotics/synbiotics prevent postoperative infections in patients undergoing abdominal surgery? A meta-analysis of randomized controlled trials. Eur J Clin Pharmacol. 2009;65(6):561-70. doi: 10.1007/s00228-009-0642-7. [PubMed: 19326107].

40. Wang Y, Li X, Ge T, Xiao Y, Liao Y, Cui Y, et al. Probiotics for prevention and treatment of respiratory tract infections in children: A systematic review and meta-analysis of randomized controlled trials. Medicine (Baltimore). 2016;95(31). e4509. doi: 10.1097/MD.0000000000004509. [PubMed: 27495104]. [PubMed Central: PMC4979858].

41. Shida K, Sato T, Iizuka R, Hoshi R, Watanabe O, Igarashi T, et al. Daily intake of fermented milk with Lactobacillus casei strain Shirota reduces the incidence and duration of upper respiratory tract infections in healthy middle-aged office workers. Eur J Nutr. 2017;56(1):4553. doi: 10.1007/s00394-015-1056-1. [PubMed: 26419583]. [PubMed Central: PMC5290054].

42. Heidarian F. The effect of probiotics on prevention of nosocomial pneumonia. Medical Journal of Mashhad University of Medical Sciences. 2014;52(6):799-803.

43. Ling Z, Liu X, Guo S, Cheng Y, Shao L, Guan D, et al. Role of probiotics in Mycoplasma pneumoniae Pneumonia in children: a short-term pilot project. Front Microbiol. 2018;9:3261. doi:10.3389/fmicb.2018.03261.
[PubMed: 30687259]. [PubMed Central: PMC6334620].

44. Watkinson PJ, Barber VS, Dark P, Young JD. The use of pre- pro- and synbiotics in adult intensive care unit patients: systematic review. Clin Nutr. 2007;26(2):182-92. doi: 10.1016/j.clnu.2006.07.010. [PubMed: 17011083].

45. Alexandre Y, Le Blay G, Boisrame-Gastrin S, Le Gall F, HeryArnaud G, Gouriou S, et al. Probiotics: a new way to fight bacterial pulmonary infections? Med Mal Infect. 2014;44(1):9-17. doi: 10.1016/j.medmal.2013.05.001. [PubMed: 23820129].

46. Harata G, He F, Hiruta N, Kawase M, Kubota A, Hiramatsu M, et al. Intranasal administration of Lactobacillus rhamnosus GG protects mice from $\mathrm{H} 1 \mathrm{~N} 1$ influenza virus infection by regulating respiratory immune responses. Lett Appl Microbiol. 2010;50(6):597-602. doi: 10.1111/j.1472-765X.2010.02844.x. [PubMed: 20438620].

47. Racedo S, Villena J, Medina M, Aguero G, Rodriguez V, Alvarez S. Lactobacillus casei administration reduces lung injuries in a Streptococcus pneumoniae infection in mice. Microbes Infect. 2006;8(9-10):2359-66. doi: 10.1016/j.micinf.2006.04.022. [PubMed: 16904925].

48. Guo C, Lei M, Wang Y, Hua L, Xue S, Yu D, et al. Oral administration of probiotic Lactobacillus Casei Shirota decreases Pneumonia and increases pulmonary functions after single rib fracture: A randomized double-blind, placebo-controlled clinical trial. J Food Sci. 2018;83(8):2222-6. doi:10.1111/1750-3841.14220. [PubMed: 30020533].

49. Box MJ, Ortwine KN, Goicoechea M, Scripps Antimicrobial Stewardship P. No Impact of Probiotics to Reduce Clostridium difficile Infection in Hospitalized Patients: A Real-world Experience. Open Forum Infect Dis. 2018;5(12):ofy192. doi: 10.1093/ofid/ofy192. [PubMed: 30568976]. [PubMed Central: PMC6291414].

50. Ashraf R, Shah NP. Immune system stimulation by probiotic microorganisms. Crit Rev Food Sci Nutr. 2014;54(7):938-56. doi: 10.1080/10408398.2011.619671. [PubMed: 24499072]. 